ENSAYO

\title{
ADAM SMITH, ARISTÓTELES Y LA ÉTICA DE LA VIRTUD*
}

\author{
Ryan Patrick Hanley
}

En este artículo se sostiene que la teoría moral de Adam Smith se entiende mejor como una contribución a la ética de la virtud que como una contribución a cualquiera de las dos escuelas rivales de la filosofía moral contemporánea, el utilitarismo y la deontología.

Para demostrarlo, el autor examina la concepción que tiene Smith de los métodos y fines apropiados de la ética. Se centra aquí en el lugar que Smith le asigna a la retórica en la ética, y en cómo, para Smith, la ética se relaciona más con la formación del carácter que con el esta-

Ryan Patrick Hanley. M. Phil. Universidad de Cambridge; Ph. D. de la Universidad de Chicago. Profesor del Departamento de Ciencia Política en la Universidad de Marquette. Autor de numerosos artículos en revistas especializadas, actualmente está trabajando en su libro "Adam Smith and the Character of Virtue".

* "Adam Smith, Aristotle and Virtue Ethics", publicado en New Voices on Adam Smith, Leonidas Montes y Eric Schliesser, editores (Londres: Routledge, 2006). Versiones anteriores de este ensayo fueron presentadas en la Asamblea Anual 2001 del Eighteenth Century Scottish Studies Society en Arlington, VA, y en la conferencia anual 2001 de la American Political Science Association, en San Francisco. El autor expresa su agradecimiento a los participantes de ambas conferencias, especialmente a Lauren Brubaker, Doug Den Uyl, Sam Fleischacker, Leonidas Montes, Jim Otteson y Eric Schliesser, por sus numerosas y útiles sugerencias.

Traducción al castellano de Estudios Públicos. Su publicación en esta edición cuenta con la debida autorización.

Para las abreviaciones y referencias de las obras de A. Smith, véase sección a) de las referencias bibliográficas al final del artículo. 
blecimiento de reglas y preceptos. Se concluye, sobre esa base, que Smith debe ser considerado junto a Hutcheson y Hume como uno de los fundadores en el siglo XVIII de la ética de la virtud contemporánea, y que, al igual que los cultores de esta última, le debe mucho a Aristóteles y, de hecho, bien puede servir de interlocutor en los actuales debates neo-aristotélicos.

E ntre los fenómenos más importantes de la filosofía moral contemporánea se cuenta el surgimiento de la ética de la virtud como una alternativa viable a los enfoques tanto utilitaristas y consecuencialistas, por un lado, como a los deontológicos o kantianos, por otro lado. En contraste con estos sistemas, que evalúan los actos de acuerdo con su potencial para maximizar efectos positivos (como hacen los consecuencialistas), o de acuerdo con su decidida adhesión a reglas morales universalmente válidas (como hacen los kantianos), los filósofos de la ética de la virtud se han centrado en describir las virtudes y los vicios que determinan los buenos y los malos caracteres humanos. Al desplazar la atención desde los actos hacia el carácter de la persona, a menudo se dice que dichos filósofos reemplazan la pregunta de “¿qué es lo que debo hacer?” por la de “¿qué es lo que debo ser?"1.

La inspiración de este vuelco se atribuye con frecuencia al resurgimiento del neo-aristotelismo ${ }^{2}$. En grado menor, y más recientemente, se han rastreado los antecedentes de la ética de virtudes contemporánea hasta la filosofía moral británica de Hutcheson y Hume ${ }^{3}$. Sin embargo, a esos

${ }^{1}$ Útiles revisiones de la creciente literatura sobre la ética de las virtudes y sus planteamientos esenciales pueden encontrarse en Trianosky (1990), Stohr y Wellman (2002), así como en Copp y Sobel (2004). Sobre los desafíos de la ética de las virtudes como una coherente tercera alternativa al utilitarismo y al kantianismo, véase especialmente Nussbaum (1999) y Singleton (2002).

${ }^{2}$ La recuperación del enfoque de Aristóteles sobre la ética es el punto de partida para varias de las afirmaciones esenciales de la ética de la virtud; véase, por ejemplo, Anscombe (1958). El sitial de Aristóteles como originador de la tradición de la ética de la virtud es destacado por Alaisdair MacIntyre en varios de sus escritos y probablemente de modo más claro en MacIntyre (2001). Para las críticas de que hay una apropiación indebida de Aristóteles por parte de la ética moderna, cuyas teorías destacarían en exceso el egoísmo en la obra de Aristóteles pasando por alto su comprensión del lugar que ocupa la política en el florecimiento humano, véase Simpson (1992) y Buckle (2002).

${ }^{3}$ Darwall (2003) incluye lecturas de tres filósofos anteriores al siglo veinte: Aristóteles, Hutcheson y Hume; cf. MacIntyre (2001: 1760). Sobre la ética de la virtud de Hume, véase Homiak (2000a, 2000b). Para una evaluación crítica, véase Hursthouse (1999a: 80-81). Douglas Den Uyl también sostiene con fuerza que Shaftesbury es un “clásico de la ética de la virtud”, en Den Uyl (1998: 276 sig.). 
nombres merece ser agregado el de Adam Smith, puesto que una de las intenciones de su obra La Teoría de los Sentimientos Morales (TSM) es mostrar una orientación alternativa para la ética, una aproximación que traslada la atención desde las reglas morales hacia la educación del carácter. Más aún, a semejanza de los filósofos de la ética de las virtudes contemporáneos, también Smith está en deuda con Aristóteles ${ }^{4}$. Yuxtaponiendo aquí los enfoques de ambos pensadores, espero llamar la atención sobre una determinada parte de estas deudas, explorando de paso la investigación que lleva a cabo Smith respecto a la pregunta: ¿en qué consiste la virtud?, o, como él la glosa: “¿cuál es el tono del temperamento y el tenor de la conducta que constituyen el carácter excelente y digno de elogio, aquel carácter que es el objeto natural de la estima, la honra y la aprobación?” (TSM VII.i.2, $265)^{5}$. Espero que la respuesta aristotélica que da Smith a esta interrogante fundamental de la ética de la virtud sea de interés tanto para los especialistas en Smith como para la filosofía moral contemporánea ${ }^{6}$.

\section{Las formas de la ética y el lugar de la retórica}

En la última sección de la parte final de TSM, Smith concluye describiendo su manera de entender el papel de la ética en la educación del carácter. Lo hace en el curso de una investigación de los métodos apropiados para "la ciencia que con propiedad es llamada ética" (TSM VII.iv.6, 329). En este mismo pasaje desarrolla una distinción ya esbozada anteriormente en-

${ }^{4}$ Otros comentaristas han desarrollado con mucha lucidez la deuda de Smith con Aristóteles en otras materias. Sobre la justicia, véase Berns (1994); sobre la amistad, véase Den Uyl y Griswold (1996: esp. 616, 634); sobre las virtudes comerciales, véase Calkins y Werhane (1998); sobre la sabiduría práctica, véase Fleischacker (1999) y Carrasco (2004); sobre el dominio de sí mismo y el punto medio, véase Vivenza (2001: 46 sig.) y Montes (2004: 81-86). El presente estudio busca complementar a éstos mostrando todavía otro punto de acuerdo, en base al común entendimiento del carácter y del rol de la ética en su educación.

${ }^{5}$ Las referencias a las obras de Aristóteles son las siguientes: EN, Ética Nicomaquea; $P$, Política; $R$, Retórica. En los pasajes que cito de la Ética y la Retórica sigo generalmente las traducciones (al inglés) de Rackham (Loeb) y Kennedy (Oxford), respectivamente.

${ }^{6} \mathrm{Al}$ sentar a conversar a Smith y Aristóteles, mi intención no es dar cuenta de la directa apropiación que hace el primero del segundo. Un extenso estudio al respecto fue desarrollado, en todo caso, por Vivenza en su admirable Smith and the Classics. Personalmente me he beneficiado con la advertencia de la misma autora de no buscar una "llave de interpretación en particular [...] basada en una filosofía clásica reelaborada por mentes modernas" (Vivenza, 2004: 117). Estoy agradecido de la profesora Vivenza por permitirme leer el manuscrito antes de su publicación. 
tre "dos modos diferentes" de tratar las reglas éticas (TSM VII.iv.2, 327). Al primero Smith lo vincula con aquellos filósofos que se centran en la justicia y que apuntan a articular reglas para la acción justa que "sean exactas en el más alto grado y no admitan excepción o modificación alguna”. Smith concuerda en que ese rigor es plenamente apropiado para las reglas de la justicia; piensa también, que para la estabilidad de la sociedad dichas reglas deberán ser "sagradamente observadas" por todos (TSM III.6.10, 175). Pero también insiste en que no se puede esperar rigor semejante de las reglas que gobiernan todas las demás virtudes. La justicia, apunta, "es la única virtud para la cual se pueden dictar propiamente esas reglas tan exactas" (TSM VII.iv.7, 329). Sus reglas son "las únicas reglas de moralidad que son precisas y exactas", en cambio "aquellas pertenecientes a todas las demás virtudes son flexibles, vagas e indeterminadas” (TSM VII.iv.1, 327). Esperar, cuando hablamos de otras virtudes, dice Smith, la misma rigurosa adhesión a las reglas como la que esperamos en el caso de las reglas de la justicia, “evidentemente sería la más absurda y ridícula pedantería” (TSM III.6.9, $174)^{7}$.

Sobre esta base, Smith sugiere que los filósofos que buscan tratar otras virtudes que no sea aquella de la justicia, requieren de un método diferente de aquel usado por los que se centran únicamente en la justicia. Ahora bien, en cierto sentido todo el objetivo de esta sección final de la última Parte de La Teoría de los Sentimientos Morales reside en separar los métodos apropiados para la ética y para la jurisprudencia natural. Pero Smith también quiere mostrar que la combinación realizada por los filósofos de estos dos métodos diferentes ha llevado a una innecesaria confusión al interior de la filosofía moral como un todo. De ahí que Smith distinga dos métodos para la ética: aquel de los que actuando como "críticos" aplicaron a la totalidad de las virtudes "ese método impreciso hacia el cual fueron encauzados naturalmente por considerar una sola especie de virtudes”, y aquel de los que actúan como "gramáticos", quienes al tratar las virtudes se han "esmerado universalmente en introducir en sus preceptos aquel tipo de exactitud del que son capaces sólo unas pocas de ellas” (TSM VII.iv.2, 327). Ambas especies de ética están en cierta medida equivocadas, por cuanto cada una aplica a toda la gama de la virtud métodos apropiados para sólo una parte de ella. Pero Smith prefiere el método de los críticos porque estima que es más adecuado para aquellas virtudes que son propiamente materia de la ética, mientras que aquél de los gramáticos sólo se puede

${ }^{7}$ Compárese la crítica de Smith con aquellas de los críticos de la filosofía moral contemporánea expuestas por Baier (1985) y Hursthouse (1999b); cf. Stohr y Wellman (2002: 55). 
aplicar a la justicia, materia propia de la jurisprudencia natural ${ }^{8}$. Smith elabora este punto en su crítica a los casuistas. "Tanto los casuistas de las épocas medievales como los más recientes de la iglesia cristiana” y "todos aquellos que en este siglo y en el anterior se han ocupado de la llamada jurisprudencia natural", nos explica Smith, hacen uso del enfoque de los gramáticos (TSM VII.iv.7, 329) ${ }^{9}$. Sin embargo, los legisladores inspirados en la jurisprudencia natural aplicaron este método para sentar reglas de justicia con mucho más éxito que el que tuvieron los casuistas que anhelaban "prescribir reglas para la conducta del hombre bueno" (TSM VII.iv.8, 330 $)^{10}$. Smith no puede aprobar esos métodos para tales fines; de ahí su crítica a los casuistas por intentar, "sin resultado alguno, dirigir mediante reglas precisas lo que compete ser juzgado únicamente por el sentir y los sentimientos". Sus obras nada valen en cuanto aporte a la ética: "secas y desagradables" y llenas de aquella "frívola exactitud" que buscaron imponer a "materias que no la admiten”. La crítica de Smith a la casuística concluye con su insistencia en que los trabajos propios de ésta abundan en "distinciones abstrusas y metafísicas", siendo "incapaces de despertar en el corazón ninguna de esas emociones que precisamente deben despertar los libros morales". De esta forma fracasan en "animarnos para lo que es generoso y noble" o "suavizarnos para lo que es gentil y humano" (TSM VII.iv.33, 339-340). Sin embargo, ahí donde fracasan los gramáticos triunfan los críticos morales; éstos "nos muestran una idea general de aquella perfección a la que deberíamos aspirar, más que proporcionarnos directrices ciertas e infalibles para alcanzarla” (TSM VII.iv.1, 327; III.6.11, 175-176) ${ }^{11}$. Ellos nos muestran "agradables y vívidas representaciones de los modos de ser", en un esfuerzo por "inflamar nuestro natural amor a la virtud e incre-

${ }^{8} \mathrm{Al}$ reconocer Smith que la naturaleza de la justicia requiere ser tratada de un modo diferente que las otras virtudes éticas, anticipa y de ese modo evita una de las más comunes objeciones a la ética de virtudes contemporánea, precisamente, que fracasa en suministrar una defensa suficiente de la justicia; véase, por ejemplo, Stohr y Wellman (2002: 68).

${ }^{9}$ En $R N$ Smith usa el ejemplo de la casuística para ilustrar la diferencia fundamental entre la "filosofía moral antigua" y la "filosofía moderna", a saber, que mientras en la primera "los deberes de la vida humana son tratados como subordinados a la felicidad y a la perfección de la vida humana, en la modernidad se reemplaza la aspiración a la "perfección de la virtud" y a la "felicidad y perfección del hombre" por una moralidad ascética centrada en una vida futura ( $R N$ V.i.f.30, 771).

${ }^{10}$ Para una excelente discusión de los orígenes y el modo de operar de esas reglas morales generales respecto a la justicia, véase Fleischacker (1999: 41-55).

${ }^{11}$ La formulación de Smith evoca la distinción del propio Hume entre "dos diferentes modos" de filosofía moral en la primera sección de An Enquiry Concerning Human Understanding $(E H U)$ 1.1-2, y especialmente su distinción entre el artista y el anatomista en $E H U$ 1.8. 
mentar nuestro aborrecimiento del vicio”. Cuando sus retratos morales están vestidos “con los ornatos de la elocuencia”, insiste Smith, son “capaces de producir las impresiones más nobles y duraderas sobre la ductibilidad de la juventud”, que con el pasar del tiempo confirman en ellos los hábitos más nobles y más útiles (TSM VII.iv.6, 329) ${ }^{12}$.

Smith en general identifica el método crítico de la ética con los trabajos de los “antiguos moralistas” que rechazan la "primorosa exactitud”, propia de la casuística, y en su lugar buscan describir al carácter excelente (TSM VII.iv.34, 340; VII.iv.3, 328). Smith incluso tiene en mente algunos de sus ejemplos favoritos, y se refiere a "Cicerón, en el primer libro de los Oficios”, y a “Aristóteles, en las partes prácticas de su Ética”, como particularmente excelentes (TSM VII.iv.5, 329). Ahora bien, la deuda que con Cicerón tienen la Ilustración Escocesa y, en particular, Smith ha sido latamente examinada ${ }^{13}$. Pero la adhesión de Smith a Aristóteles podría hacer titubear a los lectores. En la superficie, un considerable abismo parece separar a Smith de Aristóteles. Bástenos con recordar aquí varias de las diferencias cruciales ya mencionadas, incluyendo el silencio aparente de Smith sobre la teleología ${ }^{14}$, su silencio aparente sobre las virtudes intelectuales ${ }^{15}$, su aparente defensa de la vida comercial, que Aristóteles desecha por hedonista ${ }^{16}$, su aparente igualitarismo ${ }^{17}$ y su aparente redefinición de la vida próspera entendida más bien como cooperación social que como autoperfeccionamiento individual ${ }^{18}$. Esas diferencias bien pueden ser insuperables y bien podría ser que el proyecto de Smith y el proyecto de Aristóteles simplemente no sean coincidentes. Al mismo tiempo, sin embargo, intentar "rescatar" a Smith de tales eventualidades podría resultar descaminado; en cualquier caso,

12 Desde luego que los matices de Smith deben recordarse todo el tiempo. Dichos sistemas, insiste aquí, alcanzan todo lo que "el precepto y las reglas pueden hacer para animarnos a practicar la virtud” (TSM VII.iv.6, 329), pero los límites de tales sistemas ya han sido claramente advertidos (TSM VII.ii.4.5, 307).

${ }^{13}$ Las deudas específicas de Smith con Cicerón son destacadas por Waszek (1984); cf. Vivenza (2001:3-4, 42, 66, 191-194); y la respuesta dada en Montes (2004: 124-128).

${ }^{14}$ Véase especialmente Griswold (1999: 4-5, 315-316, 332-333). Véase también Werhane (1991: 49); cf. Fleischacker (1999: 147-151).

${ }^{15}$ Véase especialmente Cropsey (1957: esp. 49-50).

${ }^{16}$ Véase especialmente Calkins y Werhane (1998: 43 sig.).

${ }^{17}$ Véase especialmente Fleischacker (1999: 161); cf. Waszek (1984: 591 sig.)

${ }^{18}$ Véase especialmente Den Uyl (1998: 316): "Para Smith, entonces, el problema de la virtud en los tiempos modernos se resuelve mediante el rechazo del elitismo clásico que define a la virtud en términos del perfeccionamiento del alma individual, centrándose en cambio en sentimientos conducentes a la cooperación social”; cf. Den Uyl y Griswold (1996: 617); Den Uyl (1991: 137) Cropsey (1957: 38); cf. Fleischacker (1999: 140-144). 
no es lo que se intentará hacer aquí. Lo que para mí resulta más interesante es la reconstrucción de los motivos de la admiración que Smith sentía por ese “filósofo que ciertamente conocía el mundo" (TSM VI.iii.44, 258) ${ }^{19}$. Dada la profunda brecha que parece separar el mundo de Aristóteles de aquel de Smith — una brecha de la que Smith difícilmente pudo no darse cuenta-, ¿cuáles son precisamente los elementos de la ética de Aristóteles que Smith sí admiraba y buscaba recuperar?

El mismo Smith apunta a ciertos elementos substantivos, como es evidente en su observación de que la descripción que hace Aristóteles de la virtud corresponde con "bastante exactitud" a lo que él mismo dice acerca de lo propio y lo impropio en TSM (TSM VII.ii.1.12, 270-271). Sin embargo, más sugerentes que esta similitud en sus afirmaciones substantivas son varias similitudes en sus conceptos de los métodos y los fines de la ética. Como hemos visto, Smith insiste en que la ética debería animar a quienes la estudian para lo que es noble, y al hacerlo sigue muy de cerca la insistencia de Aristóteles en que la meta principal de la indagación ética es nuestro efectivo mejoramiento (EN, 1103b26-31; 1179a33-1179b4). El interés que sentía Smith por el resultado práctico de la indagación ética no es menos pronunciado; de ahí su lamentación de que el espíritu de su época se hubiese inclinado hacia "razonamientos abstractos y especulativos, que probablemente tienden muy poco al mejoramiento de nuestra praxis", particularmente en las "ciencias prácticas de la política y la moralidad o ética" ( $L R B L$, Lección 8, i.101-102, 41). Ahora bien, la distinción consciente que hace Smith entre las ciencias abstractas y especulativas, por un lado, y las ciencias prácticas de la política y la ética, por el otro, invita a un examen más acucioso de su concepto de los diversos modos de investigación apropiados para cada tipo de ciencia. La aseveración de Smith de que la ciencia de la ética no admite "siquiera la más aguda precisión”, evoca la característica insistencia de Aristóteles en que el nivel de precisión que puede esperarse de tipos más rigurosos de investigación difícilmente puede esperarse de las teorías de la ética, debido a la naturaleza de su contenido (TSM VII.vi.6, 329; VII.iv.33, 339-340; cf. EN 1094b11-14; 1098a26-29; 1103b34-1104a11). A semejanza de Smith, también Aristóteles afirma que el objetivo de la ética es menos establecer reglas generales de acción que cultivar el juicio o la sabiduría práctica necesarios para la acción correcta en situaciones particulares (EN 1104a5; 1109b18-23; 1126a31-1126b4). (Esta afirmación aparece muy bien desarrollada en Sherman, 1989: 13 y sig.) De modo que ambos pensadores concluyen que la precisión no es una meta apropiada para los estu-

${ }^{19}$ Fleischacker destaca que "Aristóteles es el único filósofo moral que no es objeto de críticas” en todo TSM; véase Fleischacker (1999: 122). 
diosos de la ética; es más, la distinción que Smith hace entre gramáticos y críticos está anticipada en la distinción que hace Aristóteles entre la rudimentaria pero efectiva ciencia de los carpinteros y la ciencia más precisa de los geómetras (EN 1098a29-32), y en su afirmación de que no debe esperarse el mismo grado de exactitud de los oradores que de los matemáticos ( $E N$ 1094b25-27).

El concepto que Smith y Aristóteles comparten en cuanto a la naturaleza imprecisa de la ciencia de la ética los llevó a comprender de un cierto modo cómo deberían los autores presentar al público las premisas éticas. Siendo la materia de la ética lo que es, Aristóteles enseña que los autores harían bien en comenzar presentando sólo esquemas simples de la verdad y no difíciles definiciones, especialmente al comienzo (EN 1094a24-26; 1094b19-23; 1098a20-26). Desde luego, su Ética hace precisamente eso. Partiendo por lo dado ("el que"), su indagación comienza con un "boceto elemental”, a partir de lo que ya es familiar para su audiencia, y luego va completando a medida que se desplaza poco a poco desde la opinión común hacia la verdad (cf. 1145b2-7). Este tipo de enfoque, si bien necesario dada la naturaleza de la materia propia de la ética, también se hace necesario debido a la naturaleza de los lectores a los que habitualmente se dirigen los tratados de ética. Nadie, sino los estudiantes mejor dispuestos, puede ser encaminado hacia la virtud únicamente a través de libros teóricos, cosa que Aristóteles sabe. A la mayoría de las personas las mueve más el afán de ganancia y el amor al placer que el amor de lo que es noble (EN 1179b4-16). En consecuencia, si se espera poder guiar a una audiencia compuesta de amantes del placer o de amantes del honor hacia el amor por lo noble, será necesario apelar, al menos al comienzo, a sus opiniones e inclinaciones instintivas ${ }^{20}$. De este modo, Aristóteles concluye que la forma de retórica apropiada para los tratados de ética difiere de aquella usada por los tratados de metafísica. La mayoría de los hombres, incapaces de razonar desde puntos de vista diversos, o de ver varias cosas a la vez, son motivados sólo por cuestiones más inmediatas (Retórica 1395b25-1396a1). Argumentos largos e intrincados, basados en proposiciones universales, siempre tendrán menos poder de convicción en esas personas que argumentos fundados en pormenores con los que ya están familiarizados a través de su experiencia (R 1395b25-1396a1).

La comprensión que tiene Aristóteles del lugar central que ocupa la retórica en la ética halla eco en Smith. En particular, Smith acoge la distin-

${ }^{20}$ Véase especialmente EN 1098b9-12 y $R$ 1356b33-1357a4; 1395b20-1396a3. Mi forma de comprender la dialéctica de Aristóteles y su concepto de endoxa está en deuda en particular con Tessitore (1998) y Jaffa (1952). También Griswold reconoce los métodos de Smith como “vastamente aristotélicos” en este sentido; véase Griswold (1999: 58). 
ción que hace Aristóteles entre aquellos enfoques que conducen a primeros principios y aquellos que toman a los primeros principios como punto de partida (EN 1095a30-b4). Lo que Aristóteles quiere decirnos aquí es que las indagaciones éticas y políticas deberían tomar como punto de partida algo que ya es familiar para la audiencia, más que partir por primeros principios. Se trata de una convicción compartida por Smith. En la conclusión de su vigésima cuarta Lección de retórica, Smith explica que el método de escribir e indagar, que es "indudablemente el mejor en todas las materias de las ciencias", es inapropiado para los "discursos retóricos", debido a sus diferentes audiencias. Al igual que Aristóteles, insiste en que los habituales destinatarios de éstos "no hallan placer en esas abstrusas deducciones; su interés, y la factibilidad y honorabilidad de la cosa recomendada, es lo único que los convencerá, y esto es algo que pocas veces puede mostrarse a través de una larga deducción de argumentos” ( $L R B L$, Lección 24.ii.135, 146).

Tanto la ética de Smith como la de Aristóteles se encuentran igualmente moldeadas por este discernimiento. La belleza de la virtud, dice Smith, "es principalmente percibida por personas reflexivas y analíticas, y no es en absoluto la primera cualidad con la que esos actos se recomiendan a los sentimientos naturales del grueso de la especie humana" (TSM IV.2.11, 192). Consciente de ello, al hacer sus primeras recomendaciones en materia de virtud, destaca más su utilidad que su belleza, o incluso la belleza de su utilidad. Por supuesto que Smith no se inclina por negar la belleza abstracta de la virtud; simplemente piensa que es mejor introducirla con el tiempo y no al comienzo. El entrenamiento de ese "ojo natural de la mente" es un proceso largo y arduo (TSM III.3.2, 135; cf. EN 1104a11-14). Alzarnos hasta el punto en que nosotros, a semejanza del phronimos aristotélico, seamos capaces de "reconocer el original cuando lo encontremos", tomará tiempo y práctica y no puede acometerse frontalmente (TSM VII.iv.4, 328; cf. V.i.8. 198-199). Al igual que Aristóteles, Smith comienza nombrando aquello que habitualmente merece alabanza, sólo llegando a lo digno de alabanza (praiseworthy) o a lo noble con el tiempo.

\section{La dialéctica del amor a sí mismo (self-love) y la benevolencia}

En su exposición de la educación moral del carácter, en La Teoría de los Sentimientos Morales, Smith emplea la dialéctica ascendente descrita en sus Lectures on Rethoric and Belles Lettres (CRBL). El desplazamiento en la obra de Smith va desde aquello que es corrientemente honrado y alabado, hacia aquello que es genuinamente honorable y digno de alabanza (honora- 
ble and praiseworthy). En su calidad de educador moral, la tarea de Smith es depurar el amor a nosotros mismos que nos impulsa a preocuparnos por los bienes del interés propio y mostrar cómo el amor a sí mismo, cuando es ennoblecido, puede conducir a aquel amor por lo noble que distingue a los hombres de sabiduría y de virtud. Nuestra tarea será, entonces, esbozar ese movimiento dialéctico de TSM y demostrar su relación con la dialéctica de Ética a Nicómaco ${ }^{21}$.

Por ahora podríamos comenzar señalando que ambas obras inician sus argumentaciones en favor de la virtud ética con una insistencia en la utilidad que ella tiene cuando nos asiste en la obtención de bienes externos, habitualmente valiosos. TSM comienza apelando precisamente a esa preocupación por la honra y el interés que en sus Lectures on Rethoric insiste en señalar como la fuerza que impulsa a la mayoría de las personas. Al hacerlo, Smith actúa de acuerdo con el principio que subyace en su respuesta explícita a Epicuro: cuando los hombres, a través de sus actos, "ponen de manifiesto que la belleza natural de la virtud no parece tener gran efecto sobre ellos, ¿de qué otro modo es posible motivarlos que no sea demostrándoles la insensatez de su conducta y lo expuestos que están ellos mismos a sufrir bajo las consecuencias de esa insensatez?" (TSM VII.ii.2.13, 298-299). De acuerdo con este consejo, Smith comienza TSM con un análisis de lo correcto (propriety) y de las virtudes que se relacionan con la promoción del interés. Ahora bien, incluso al tomar nota de esto debemos recordar que Smith difícilmente defenderá un interés propio desnudo; aunque ése fue el retrato que alguna vez estuvo de moda, en los hechos Smith se afanó en disociar su sistema moral de los "sistemas licenciosos" de La Rochefoucauld y de Mandeville, y de otros proponentes del egoísmo psicológico que redujeron toda virtud al interés (véase especialmente TSM VII.ii.4, 308 y sig.). Como indica la primera frase de la obra, la Parte I no argumenta en favor de la supremacía de las pasiones inducidas por terceros, como tampoco lo hace en favor de aquellas egoístas, sino que más bien apunta a explicar cómo operan juntas. Al tratar este tema, la Parte I sienta los fundamentos de la respuesta que Smith da a la segunda de ambas interrogantes descritas en VII.i.2, es decir, a la pregunta por las fuentes del juicio moral. Pero en cuanto la Parte I también se refiere a la primera interrogante descrita

${ }^{21}$ Sobre la "dialéctica” de Smith, véase también Den Uyl y Griswold (1996: 611); Lerner (1999: 65); Skinner (1979: 45). Véase también la interpretación de Griswold respecto a TSM: la considera "una historia que se va desenvolviendo a pasos" (Griswold, 1999: 61, 331); y la aseveración de Macfie de que TSM expone una "teoría de valores individuales graduados" y un "registro psicológico del avance desde la vanidad hasta la magnanimidad” (Macfie, 1967: 54, 72), que constituye en realidad una lectura bastante cercana a la noción de la dialéctica del amor a sí mismo que pretendo desarrollar aquí. 
en VII.i.2 —es decir, aquella de "en qué consiste la virtud”-, también presenta lo correcto (propriety) y las virtudes del amor a sí mismo como preparación para apreciar la virtud genuina.

La Parte I parece centrarse en el papel del interés propio, tanto en la vida individual como en la social. Es aquí donde Smith nos dice que la vanidad y la ambición, fuentes de nuestro deseo de llegar a ser el objeto de la atención y la aprobación de otros, gobiernan nuestras actividades más características: los intentos de mejorar nuestra condición a través del afán de riqueza y de mejorar nuestra posición a través de la búsqueda de poder político y rango social (TSM I.iii.2.1, 50-51). Los ricos y los grandes, se nos recuerda además, siempre son mucho más admirados que los sabios y los virtuosos. Mayor es el número de las personas que estiman más una vida "llamativa y relumbrante en su colorido" que se impone por sí misma "a la percepción de cada ojo errante", que la vida "más exquisitamente hermosa en su contorno" que atrae la atención "de apenas unos pocos, los más estudiosos y atentos observadores” (TSM I.iii.3.2, 62; cf. Riqueza de las Naciones V.i.b.5, 711). Por supuesto que también Aristóteles sabe que el honor y la riqueza atraen mayor número de admiradores que la virtud y la sabiduría; el concepto popular de felicidad se funda en la obtención de bienes palpables como placer, riqueza u honor (EN 1095a17-28; cf. TSM VI.ii.1.20, 225-226). Más allá, también Aristóteles nota que, en su raíz, el uso de la riqueza está íntimamente vinculado con la afición por la estima y la admiración (EN 1123a18-27; TSM I.iii.2.1, 50-51; VI.i.3, 212-213). Sin embargo, en lugar de lamentar esta disposición tan común, ambos pensadores la ponen a trabajar desde un comienzo, dado que cada uno sabe que el modo más efectivo de conducir a las audiencias populares a la virtud reside en apelar a lo útil que ella es para ayudarlos a alcanzar los objetivos de sus deseos innatos. En consecuencia, a quienes esperan mejorar su condición, Smith recomienda probidad y prudencia, industriosidad, independencia de espíritu y fortaleza frente al sufrimiento y la aflicción (TSM I.iii.2.5, 54-56). Para quienes se estiman exitosos, recomienda prudencia y discreción, a fin de no cortejar la envidia de otros (TSM I.ii.5.1, 40-41; $R$ 1387a15). Destacando la utilidad de las virtudes para reclamar y mantener las recompensas, Smith habla a su audiencia en un lenguaje al cual ésta parece estar predispuesta. Al hacerlo, Smith revela su compromiso con la creencia de que tener éxito en la búsqueda de la riqueza y del honor exterior "es la recompensa más adecuada para alentar la industria, la prudencia y la discreción” (TSM III.5.8, 166-167) 22 .

${ }^{22}$ De modo que si bien Aristóteles y Smith se dirigen claramente a públicos diferentes, ambos buscan elevar a los elementos bien dispuestos en sus respectivas audiencias a una vida mejor que aquella característica de sus congéneres. Tal vez Smith enfrenta 
Ahora, si la Parte I muestra a sus lectores un modo más conveniente de adquirir bienes externos, la Parte II marca el comienzo de un ascenso. Al desplazar el enfoque de la indagación desde lo correcto (propriety) hacia el mérito, la Parte II hace un giro desde el reclamo de bienes hacia el merecimiento. Aquí Smith va más allá de lo que es comúnmente honrado, para proceder al examen de aquellas actividades por las cuales los seres humanos efectivamente merecen ser honrados. Hacia el final de la Parte II, ya no quedan dudas respecto de cuáles son esas actividades. "Actos de tendencia benéfica, que proceden de motivos probos, parecen ser los únicos que requieren premiarse” (TSM II.ii.1.1, 78). Como vamos aprendiendo, el virtuoso avance de uno mismo con que comenzó la obra de Smith es solamente el primer paso de un recorrido mucho más largo; de hecho estas actividades corren en un distante segundo lugar en cuanto a naturalidad y nobleza respecto a aquellas actividades que promueven el bienestar de otros. Smith lo deja en claro en su mordaz crítica al sentimiento de lástima. A pesar de toda su fama como exponente de la simpatía (sympathy) por el otro, Smith no tiende a encontrar valiosa cualquier forma de simpatía. De ahí su crítica a aquella "simpatía engañosa" que nos lleva a derramar "lágrimas compasivas", lágrimas, como él insiste, que no son "sino una pequeña parte de la deuda" que tenemos para con los que sufren. Mejor que "la indolente y pasiva conmiseración” de este tipo de simpatía por el prójimo es, en consecuencia, "el sentimiento más vigoroso y activo" que nos conduce a aprobar los esfuerzos efectivos en tal sentido (TSM II.i.2.5, 70-71). De ahí su crítica a "las simples buenas inclinaciones y amables deseos":

El ser humano fue hecho para la acción y para promover mediante el ejercicio de sus facultades los cambios en las circunstancias exteriores suyas y de los demás que parezcan más favorables para la felicidad de todos. No debe darse por satisfecho con una benevolente indolencia, ni imaginarse a sí mismo como amigo de la especie humana sólo porque en su corazón desea lo mejor para la prosperidad del mundo. Debe movilizar todo el vigor de su alma y tensar cada nervio a fin de lograr aquellos fines que constituyen el propósito de su existencia. La naturaleza le ha enseñado que ni él ni la huma-

un mayor desafío en cuanto su audiencia parte del punto inferior del placer por los bienes externos, que Aristóteles desecha por no estar a la altura de su indagación. El hecho de que Smith se vea obligado a comenzar desde este punto más bajo puede explicar, acaso no disculpar, su fracaso en ascender a una defensa plena de las virtudes intelectuales. En cualquier caso, Smith parece querer trascender lo que MacIntyre considera la irreconciliable división que separa al mundo clásico o aristotélico del gentilhombre del moderno mundo mercantil "frankliniano"; véase MacIntyre (1984: 181-203). 
nidad pueden quedar plenamente satisfechos con su conducta, ni obtendrían el máximo aplauso, a menos que los hayan alcanzado. (TSM II.iii.3.3, 106)

La mera "benevolencia indolente" jamás llega a la altura de una beneficencia positiva; las buenas disposiciones corren en un distante segundo lugar detrás de las buenas acciones que producen resultados. De ahí la crítica de Smith a la emotiva o "extrema simpatía” para con aquellos cuyas condiciones no podemos mejorar; esta disposición Smith la califica de "perfectamente inútil” (TSM III.3.9, 140). También insiste en que la compasión que falla en motivar acciones positivas capaces de beneficiar a otros es de escaso valor (TSM I.ii.4.3, 40; VI.iii.15, 243). Ahora, en marcado contraste, al ser "conducentes al mayor de los bienes", los esfuerzos activos de beneficencia "merecen la mayor de las recompensas", mucho mayores que los merecimientos del hombre compasivo e, incluso, del hombre justo, "que no realiza bien positivo alguno" con permanecer tranquilamente sentado sin dañar a nadie (TSM II.ii.1.9, 81-82; cf. EN 1155a22-8) ${ }^{23}$. De modo que, si el hombre está realmente hecho para la acción y la actividad benéfica en particular, promover el bienestar de otros es descubrir los fines mismos de nuestra naturaleza. La implicancia de la cita de más arriba pareciera ser que solamente en la actividad benéfica hallaremos nuestro más pleno florecimiento como seres humanos integrados, trabajando expresamente en promover los fines para los cuales hemos sido hechos.

Smith parece estar lejos de Aristóteles cuando recomienda la actividad benéfica como el fin propio de la naturaleza humana. Como todos sabemos, de acuerdo con Aristóteles la mejor vida para el hombre no se encuentra en la vida de la virtud ética — y mucho menos aún en la vida dedicada a la virtud específica de la beneficencia - sino que en la vida de contemplación, en el ejercicio activo del principio racional del alma (EN 1098a7-18; $\left.1178^{\mathrm{a}} 6-8\right)^{24}$. Sin embargo, a pesar de esta famosa conclusión,

${ }^{23}$ Montes entrega un excelente resumen de la distinción entre benevolencia y beneficencia en el pensamiento de Smith ( $\mathrm{y}$ en Hutcheson y Bentham), en Montes (2004: 106 n. 14). La misma distinción también es central en la filosofía moral contemporánea. De ahí que William Frankena explica que "la benevolencia es una cosa de intención, no de resultado; la beneficencia es una cosa de resultado y no de intención, aunque pueda ser intencional”. Sin embargo, Frankena matiza esta afirmación de un modo que no habría sido familiar a Smith, insistiendo en que la benevolencia debería ser distinguida de "un mero desear bien, o tener buenas intenciones", por cuanto benevolencia "significa tener la voluntad y, genuinamente, tratar de hacer o de generar el bien y no el mal” (Frankena, 1987: 2); este punto es también desarrollado en Livnat (2004: 309-310).

${ }^{24}$ Claro que esta concepción ha sido objeto de intenso debate; para un ejemplo reciente de éste, véase la respuesta de Lear (2004) a Kraut (1989). 
Aristóteles también ofrece una descripción de la actividad benéfica bastante similar a la de Smith. En su discusión de la amistad explica que la actividad benéfica ofrece a los individuos una oportunidad para su desarrollo personal. De ahí, explica Smith, que los benefactores amen más a los favorecidos con sus dádivas que lo que los beneficiados aman a sus benefactores (EN 1168a3-9). Pero la distinción que hace Smith entre benevolencia indolente y beneficencia activa encuentra precisamente su paralelo en la distinción que hace Aristóteles entre buena voluntad (eunoia) y buena acción (euergeia). Al igual que Smith, Aristóteles piensa que estamos hechos por la naturaleza para llegar a simpatizar con alguien antes de haber reflexionado. La eunoia, destaca Aristóteles, puede producirse de modo instantáneo, tal como arrancan los "competidores de una carrera; los espectadores sienten buena voluntad y simpatía hacia ellos, pero no los asistirían de modo activo”. Al igual que Smith, también Aristóteles reconoce que dicha buena voluntad "es una erupción repentina, y el amable sentimiento es sólo superficial” (EN 1166b34- 1167a3). Abandonada a sus mecanismos, la buena voluntad del espectador es débil; en ausencia de afecto, la eunoia jamás llega a transformarse en esa preocupación más profunda y más substancial que puede movernos a actuar. De modo que los espectadores sienten buena voluntad por aquellos a quienes ven, pero nunca "los asisten activamente" ni se tomarían ninguna "molestia por ellos" (EN 1167a10). Por esto, la eunoia es sólo el punto de partida de la amistad, el primer vislumbre de una disposición verdaderamente útil (EN 1167a3) ${ }^{25}$.

De modo que Aristóteles, igual que Smith, enfatiza la superioridad de las buenas acciones reales sobre el mero potencial de buenas acciones que representa la buena voluntad. Pero Aristóteles enfrenta aquí un problema. Si la eunoia es solamente el comienzo, ¿qué es lo que nos conduce a la euergeia? ¿Con qué medios se hace realidad el potencial de una disposición virtuosa? También Smith debe encarar este problema: si el mérito consiste en realizar buenas acciones, pero la benevolencia es demasiado débil para llevarlas a cabo, ¿̇a qué otro mecanismo de mayor fuerza podemos apelar

${ }^{25}$ Los filósofos de la ética de la virtud contemporáneos se han visto aproblemados por la aparente falta de compromiso de Aristóteles con el humanitarismo: véase, por ejemplo, Slote (2000: esp. 335, 344). Pero la consciente distinción que hace Aristóteles entre eunoia y euergeia y la elaboración de Smith del tema en TSM tal vez proporcionen elementos adecuados para una forma substancial y vigorosa de la beneficencia activa dentro de la ética de la virtud, cuando no para la compasión y el cuidado cosmopolitas que Slote (2000) busca defender. Respecto a esta idea, véase también el estudio de Bern sobre la relación entre la simpatía de Smith con la philanthropia de Aristóteles (Berns, 1994: 72-74). 
para acercarnos a nuestros correctos (proper) fines? Smith y Aristóteles parecen ofrecer la misma respuesta: para ser benéficos en la práctica, no es a la benevolencia que debemos apelar, sino que a lo inverso, esto es, al amor a sí mismo. Desde luego que el amor a sí mismo que tienen en mente tanto Smith como Aristóteles no es el amor propio de la vanidad. Este amor a sí mismo deriva su mayor placer en ser consciente de la merecida autoaprobación, más que en la aprobación efectiva de parte de los demás. Aristóteles distingue expresamente estas dos formas de amor a sí mismo en IX.viii, explicando que el amor a sí mismo puede ser entendido en más de un solo sentido. Su uso más común es como un término de reproche para aquellos que "se asignan a sí mismos la parte mayor del dinero, el honor, o los placeres corporales [...] las cosas que desea la mayor parte de los hombres, comprometiendo en ello sus corazones como si fuesen los mayores bienes y por los que, en consecuencia, compiten entre ellos por alcanzar". Este "tipo corriente" de amor a sí mismo mostrado por la "mayoría de los hombres” Aristóteles lo desecha como egoísmo puro, insistiendo en que aquellos que toman más que su parte de los bienes externos son "correctamente censurados” (EN 1168b15-23). Sin embargo, debajo de este amor a sí mismo ordinario yace otro, aquel del "amante de sí mismo en grado excepcional”, quien "toma para sí las cosas que son más nobles y buenas en alto grado”. Del mismo modo que "vivir de acuerdo con los principios difiere de vivir de acuerdo con las pasiones”, y que "buscar lo noble difiere de aspirar a lo que es útil”, también difiere este noble amor a sí mismo de un amor a sí mismo del tipo corriente (EN 1186b28-1169a6). Es precisamente esta distinción la que Smith recupera en la Parte III de TSM. Mientras el amor a sí mismo común examinado en la Parte I tiene sus ojos puestos en la riqueza y el poder como medios de atraer la atención y aprobación de sus pares, el amor por sí mismo más elevado está preocupado de merecer aquello que es genuinamente noble y honorable ${ }^{26}$. Aquel que es motivado por esta categoría de amor a sí mismo encuentra su máximo placer, no en la opinión de los otros, sino que en la "placentera conciencia de la recompensa merecida” por haber realizado las acciones más dignas de elogio, que son "actos de beneficencia” (TSM II.ii.3.4, 86).

${ }^{26}$ Algunos comentaristas han distinguido el amor a sí mismo del egoísmo vulgar sobre la base de que el segundo perjudica a terceros de un modo directo, mientras que el primero da origen a las virtudes del amor a sí mismo ilustrado y prudencial. Véase, por ejemplo, la introducción de los editores en TSM, 22; y la afirmación de Samuel Hollander de que para Smith “el motivo del 'amor a sí mismo' es sinónimo del de 'prudencia’”. (Hollander, 1977: 138). Pero al parecer Smith ve todavía otro amor a sí mismo más elevado, que va más allá del interés propio ilustrado, uno similar al amor a sí mismo aristotélico, que en lo que concierne a la reafirmación de la búsqueda de bienes externos la trasciende. 


\section{Magnanimidad}

Establecida esta distinción, podemos volver ahora a la presentación de la educación del carácter moral en la obra de Smith. Comienza con un estudio sobre la búsqueda de elogio (Parte I) y prosigue con el examen de aquellos actos que merecen elogio (Parte II). En la Parte III, ambas discusiones se yuxtaponen; Smith urge ahora a su lector a obtener honor realizando actos que merezcan honor. Aprendemos ahora que buscamos "no sólo ser amados, sino que ser amables; o ser aquella cosa que es el objeto natural y apropiado (proper) del amor, y deseamos "no solamente ser alabados, sino que ser dignos de alabanza; o ser aquella cosa que, si bien no debiera ser alabada por alguien, es, sin embargo, el objeto natural y propio (proper) de ser elogiado" (TSM III.2.1, 113-114). La indagación focalizada en la reclamación de honor cede paso, de este modo, a una indagación acerca de la nobleza moral. De este modo, en lo que sigue Smith centra su atención en las esperanzas del hombre noble "de no meramente obtener sino que merecer la aprobación y el aplauso de sus pares” (TSM III.2.26, 126-127; cf. III.1.7, 113).

La movida clave del giro de Smith, desde la demanda de alabanza hasta el merecimiento de alabanza, es la recuperación del noble amor a sí mismo descrito por Aristóteles. En su conocida narración del terremoto en China, Smith ofrece una completa descripción del noble amor a sí mismo que corrige al amor a sí mismo vulgar y que es lo único que puede impulsar a su poseedor a la acción. De ahí que la interrogante principal de su examen sea aquí: "Visto que nuestros sentimientos pasivos casi siempre son tan sórdidos y tan egoístas, ¿cómo sucede que nuestros principios activos muchas veces sean tan generosos y tan nobles?" Conscientes de que "siempre nos vemos tanto más profundamente afectados por cualquier cosa que nos concierne a nosotros mismos que por lo que concierne a otros hombres", Smith quiere saber "qué impulsa a los generosos en cada ocasión y a los mezquinos en muchas otras a sacrificar sus propios intereses por los intereses más importantes de otros”. Al igual que Aristóteles, una vez más rechaza la idea de que podría bastar con un sentimiento humanitario: "No es el blando poder del humanitarismo, no es esa endeble chispa de benevolencia que la naturaleza ha encendido en el corazón humano" lo que nos capacita para resistir el egoísmo natural. Para corregir esta situación requerimos de "un poder más fuerte, un motivo más vigoroso":

No es el amor por nuestro vecino, no es el amor por la especie humana lo que en muchas ocasiones nos impulsa a practicar esas virtudes divinas. Es un amor más fuerte, un afecto más 
poderoso, que generalmente se impone en tales ocasiones: el amor por lo que es honorable y noble, por la grandeza y la dignidad y la superioridad de nuestro propio carácter (TSM III.3.4, 137).

Por tanto, sólo mediante una invocación al amor a sí mismo más elevado pueden remediarse el egoísmo vulgar y realizarse nuestros verdaderos fines. Al escuchar sólo aquello que en nosotros es realmente encomiable, nos permitimos ser guiados por "una voz capaz de desconcertar a la más presumida de nuestras pasiones" —una voz que aparentemente de modo paradójico, nos enseña la lección de que "no somos sino uno más en la multitud, no mejor en ningún sentido que cualquier otro". Habiendo aprendido esta lección, ya no se acepta nuestra propensión a "preferirnos a nosotros mismos antes que a otros, de modo tan vergonzoso y ciego". Con "la conciencia de la verdadera pequeñez nuestra y de cualquier cosa relacionada con nosotros" implantada en nuestras mentes, volvemos la espalda a nuestro estrecho egoísmo para que "puedan ser corregidas las confusiones naturales del amor a sí mismo” (TSM III.3.4, 136-137).

La manera en que Smith describe este fenómeno tal vez nos haga evocar la descripción que hace Aristóteles de cómo "los sentimientos de estima que abrigamos para nosotros mismos", con el tiempo pueden hacer surgir la amistad (EN 1166a5). Después de habernos mostrado la vulgaridad de ese amor propio que apunta a bienes externos, Aristóteles nos revela en seguida los beneficios de la clase de amor a sí mismo que mueve al hombre "que ama y complace a la parte dominante de sí mismo" y que acertadamente puede llamarse "el amante de sí mismo en el más alto grado". Aristóteles no deja dudas respecto a la parte más elevada de nuestro ser. A lo largo de su libro insiste reiteradamente en que es "la parte intelectual" la que "se manifiesta como el verdadero yo del hombre" (EN 1166a17) ${ }^{27}$. En este punto puede alejarse de Smith, pero las consecuencias que Aristóteles atribuye a

${ }^{27}$ Smith de hecho afirma que "la razón, el principio y la conciencia" son el asiento de lo que es noble en nosotros, aunque su énfasis en la razón no es en absoluto tan pronunciado como el de Aristóteles; cf. Berns (1994: 87-89). ¿Pero cuán profunda ha de ser la división que tracemos? Aristóteles por supuesto alega a favor de la supremacía del intelecto, cuando para Smith el origen de la moralidad reside en el sentimiento y no en la razón; la noción misma de un "sentimiento moral" parece ajena a Aristóteles, quien sostiene explícitamente que las emociones, en cuanto ellas son irracionales, no pueden ser éticas (EN 1105b28-1106a2). Pero al mismo tiempo Aristóteles también está consciente de la necesidad de descubrir un mecanismo mediante el cual lo irracional pueda llegar a participar con lo racional (EN 1102b13-28; cf. Sherman, 1989: 2, 162164), tal como Smith parece sugerir que el espectador imparcial debería servir para llevar a la razón a influir en el sentimiento a través del juicio. 
este amor propio más elevado son las mismas que señala Smith. De ahí que lejos de llevar al que más se ama a sí mismo a preferirse a sí mismo antes que a los otros, el genuino amor propio alienta la preocupación por los demás. Por tanto, Aristóteles insiste en que el hombre bueno debiera ser por fuerza aquel que más se ama a sí mismo, no sólo porque al hacerlo vivirá de acuerdo con aquello más elevado de su persona, sino porque al hacerlo se ve inducido a actuar de un modo determinado hacia los otros. Sólo siendo un amante de sí mismo en el más elevado de los sentidos puede "beneficiarse a sí mismo al actuar noblemente y, a la vez, ir en ayuda de su prójimo" $(E N 1169 \mathrm{a} 6-15)^{28}$.

En otro pasaje de su texto, Aristóteles personifica a este hombre. Su retrato del hombre de alma grande ofrece un atisbo de cómo quien se ama a sí mismo con nobleza está dispuesto a asumir el honor y de cómo se conducirá frente a terceros. En la superficie, el hombre de alma grande parece especialmente preocupado del honor. Esto equivale a decir que parece motivado principalmente por el amor egoísta hacia los bienes externos, que pertenece al tipo de personas que tienen grandes pretensiones y que también son dignas de ellas (EN 1123b1-4). Pero el estudio que hace Aristóteles de la grandeza de alma, así como el todo del que forma parte, opera de modo dialéctico $^{29}$. Con el paso del tiempo aprendemos que el hombre de alma grande es en verdad aquel tipo de hombre para quien hasta el honor es poca cosa (EN 1124a17-20), y que no es en realidad honor, sino nobleza moral perfecta, kalokagathia, aquello que constituye el objeto de sus anhelos. Pues bien, a medida que se va desenvolviendo el capítulo nos imponemos de que la grandeza del hombre magnánimo no consiste en reclamar honores - a los cuales será indiferente hacia fines del capítulo- sino que en merecerlos por su actitud frente a los demás. Así, hacia el final de $E N$ IV.iii, Aristóteles entrega evidencia de la provocativa definición de magnanimidad contenida en su Retórica (largamente pasada por alto), en cuanto virtud que produce grandes beneficios (euergetçmatôn) ( $R$ 1366b17). Esa beneficencia no es practicada con un espíritu de compasión o de lástima, sino que más bien nace de un deseo de buscar una nobleza superior a través de actos excepcionales (EN 1124b9-18).

Desde luego, para Smith, la magnanimidad también constituye un importante concepto (TSM VI.ii.1.7, 268; VI.ii.1.12, 271; VI.iii.44, 258). (Cf. Cropsey, 1957: 26, 56-61; véase también Den Uyl y Griswold 1996: 625 n. 46).

${ }^{28}$ Para la relación entre amor a sí mismo y la actividad dirigida-hacia-otro en Aristóteles, véase especialmente Kraut (1989: capítulo 2).

${ }^{29}$ Las ideas introducidas aquí - y en particular la relación entre acciones benéficas y el amor por la superioridad — son tratadas extensamente en Hanley (2002). 
En varios pasajes llama la atención sobre la belleza del aplomo (self-command) magnánimo y la fortaleza que capacita a su poseedor para ponerse a salvo de los asaltos de la fortuna y para evitar acongojar a sus compañeros con una conmiseración comprensiva por sus infortunios. En efecto, en cuanto la admiración de Smith por el dominio de sí mismo (self-command) está ligada a su admiración por la magnanimidad, ésta puede tener un origen tanto aristotélico como estoico (TSM I.i.5.8, 25-26; I.iii.1.13-14, 47-49; EN 1100b30-3). Sin embargo, su hombre magnánimo se asemeja a aquel de Aristóteles de modo muy particular, en cuanto a que está más preocupado de merecer que de pretender. Al igual que Aristóteles, en medio del más profundo de los sufrimientos dicho hombre se consuela reflexionando sobre "los aplausos y la admiración que está a punto de merecer debido a la heroica magnanimidad de su comportamiento” (TSM I.iii.1.14, 49). Además, él también parece genuinamente indiferente ante las opiniones de terceros. Hace "cierta referencia a los sentimientos de los demás" únicamente en cuanto le importa lo que deberían pensar y no aquello que piensan en realidad:

\begin{abstract}
El hombre de la mayor magnanimidad, que desea la virtud por la virtud misma y que es totalmente indiferente a lo que de hecho son las reales opiniones de los demás sobre él, está de todas maneras encantado de pensar en lo que deberían ser esas opiniones, consciente de que si bien él mismo podría no ser honrado ni aplaudido, igual sigue siendo el objeto propio (proper) de honores y aplausos, y que si la especie humana fuese serena y sincera y consecuente consigo misma, amén de correctamente informada de los motivos y las circunstancias de su conducta, no dejaría de honrarlo y aplaudirlo. (TSM VII.ii.4.10, 310-311.)
\end{abstract}

De modo que aunque el hombre "que mientras desea merecer aprobación está al mismo tiempo ansioso de obtenerla” puede ser "loable en general", Smith insiste en que sus motivos tienen "una mayor mezcla de flaqueza humana” que los de quien actúa solamente por el deseo de merecer y no de obtener. Sólo el hombre de genuina magnanimidad actúa por el bien de lo noble - “el más sublime y divino motivo que la naturaleza humana pueda concebir" (TSM VII.ii.4.10, 310-311)—, en oposición a actuar en aras de las opiniones de los otros. Smith insiste en que tal fe en sí mismo es necesaria para ese hombre. Incluso los mayores actos de beneficencia son raras veces celebrados con el grado de consideración que merecen. Concuerda con Aristóteles en que los benefactores parecen amar más a los favorecidos con sus actos benéficos de lo que esos mismos favorecidos los 
aman a cambio (EN 1167b17-28). A sabiendas, Smith aconseja que aquellos que han de servir magnánimamente a otros harán bien en derivar placer de ese servicio, conscientes de que "de cualquier modo, malentendidos o mal interpretados", aún son "el objeto natural y correcto de aprobación” —una fe en nosotros mismos que nos conduce a ser "indiferentes al aplauso y, en cierto modo, a despreciar la censura del mundo" (TSM III.1.5, 112). Mientras más confianza tengamos en el propio juicio de nuestros méritos, más indiferentes nos haremos a los elogios de los demás, y tendremos menos necesidad de ellos para confirmar nuestros hasta ahí tambaleantes juicios sobre nuestras personas (TSM III.2.16, 122; EN 1095b26-30). En este sentido, un hombre de esta naturaleza se asemeja al amigo ideal de Aristóteles, quien trabaja sin preguntar por la recompensa; "cuando desea el bien para una persona [...] lo desea para bien de esa persona, aunque nadie llegue a saberlo" (EN 1168b1-3). Seguro del valor de su persona, dicho hombre es indiferente tanto a la maledicencia como a la alabanza de los demás.

Pero ¿dónde encontrar a semejantes hombres? La política pareciera ser un escenario improbable para tamaño genio. En general, Smith casi siempre tiende a encontrar en los hombres dedicados a la política una "excesiva admiración de sí mismos", más que una genuina indiferencia ante las loas o las censuras de otros (TSM VI.iii.27, 249; cf. VI.ii.2.18, 234). Pero la cumbre que en el mejor de los casos alcanzará el hombre político ejemplar —el "reformador y legislador de un gran Estado", que se muestra capaz de "asegurar la tranquilidad interna y la felicidad de sus conciudadanos por muchas generaciones subsecuentes”- es tan sólo esta cima de la magnanimidad. Sus esfuerzos en pos de la paz y la estabilidad, sugiere Smith, constituyen la mayor beneficencia realizable en la esfera de la política y lo vuelven merecedor de la alta consideración que se tiene a sí mismo (TSM VI.ii.2.14, 232). Tal vez en un hombre así descubramos un vislumbre de ese ser humano ejemplar, capaz de combinar las virtudes mayores con las pasiones más horribles (TSM I.i.5.5, 25; III.3.35, 152). A lo mejor éste sea el ejemplo más visible de la esperanza de Smith de que la gran virtud antigua de la magnanimidad pueda unirse a la representativa virtud moderna de la benevolencia.

\section{El carácter de la virtud y el hombre sabio y virtuoso}

La ética de la virtud de Adam Smith encuentra su más dilatada exposición en la Parte VI de TSM, "Del carácter de la virtud", agregada posteriormente a la sexta edición (1790). Smith ofrece aquí su presentación más directa de aquellas virtudes éticas que son menos propensas al trata- 
miento de reglas, a saber, la "prudencia”, la "magnanimidad justa" y el "beneficio correcto (proper)" (TSM III.6.11, 176). Los métodos que aplica Smith en este caso serán de particular interés para la ética de la virtud. Podemos observar aquí su acierto en pintar retratos morales, particularmente aquellos del hombre prudente, del estadista magnánimo y del hombre sabio y virtuoso (cf. EN 1095b14-19). Pero esta segunda sección es singularmente interesante por otra razón. El movimiento dialéctico que hemos rastreado en TSM como un todo se repite en la Parte VI como en un microcosmos. Tras examinar el papel de la virtud en la búsqueda de bienes externos, la Parte VI se eleva a un examen del tipo de virtud necesario para la nobleza moral vía una consideración sistemática de las virtudes de la prudencia, la magnanimidad y la correcta (proper) beneficencia.

La educación moral ofrecida tanto en TSM como, especialmente, en la Parte VI parece regida por la fidelidad de su autor a lo que éste llama "el gran secreto de la educación", esto es, a "dirigir la vanidad hacia los objetos adecuados” (TSM VI.iii.46, 259). Tanto en la Parte VI como en el libro en su conjunto, Smith considera el amor a sí mismo como algo posible de educar y posible de ser encauzado hacia objetos más nobles ${ }^{30}$. De modo que también la Parte VI comienza con la perspectiva común y corriente de la búsqueda de metas externas. El examen que hace Smith ahí de la "prudencia inferior” representa no sólo su estudio de la virtud más próxima al mundo mercantil de $R N$, sino que también de la virtud más estrechamente relacionada con la discusión de la corrección (propriety) y de la instrumentalidad en TSM Parte I. Ahora, es interesante observar que también Aristóteles hace hincapié en que la prudencia a veces toma la forma de una capacidad de deliberar en torno de lo que para uno es inmediatamente ventajoso ( $E N$ 1140a24-31). Este reconocimiento lo conduce a pasar rápidamente a virtudes más elevadas (EN 1141a20-22). En particular lo lleva a distinguir inmediatamente entre la prudencia que se limita a guiar el aprendizaje de los individuos en la búsqueda de su propio bien, y aquella prudencia más elevada, dedicada al gobierno político (EN 1141b29-1142a11). La distinción que hace Smith entre prudencia inferior y prudencia superior se debe precisamente a estos mismos motivos. Con todo lo respetable que sea, el hombre de pru-

${ }^{30}$ Véase también Hursthouse: "Nuestras pasiones, que desde que nacemos sentimos como una tendencia inescapable e imposible de cambiar, son en sí maleables: podemos ser entrenados y luego podemos seguir entrenándonos nosotros mismos para llegar, mediante la reflexión, a sentir nuestras pasiones de determinadas maneras y no de otras" (Hursthouse, 1999a: 81); cf. en un contexto diferente, Cropsey: "La filosofía moral ha de actuar sobre los hombres para inducirlos a buscar el bien y evitar el mal, aunque su apasionado interés en sí mismos será usado como medio” (Cropsey, 1957: 25). 
dencia inferior, sordo "a la verdadera y sólida gloria de realizar las acciones más grandes y más magnánimas”, no puede ni suscitar ni merecer nuestra más alta aprobación (TSM VI.i.13, 216). Su circunspección es afable, pero nunca podremos considerarla como "una de las más cautivadoras, o más ennoblecedoras virtudes"; semejante hombre sólo puede despertar nuestra "fría estimación” y "no parece destinado a ninguna especie de amor ardiente o admiración” (TSM VI.i.14, 216) ${ }^{31}$. Lo que alguna vez pareció admirable no es, entonces, nada más que "vulgar prudencia", en contraste con la "prudencia superior", que abarca no solamente lo apropiado (propriety) sino también el coraje, la justicia, el dominio de sí mismo (self-command) y la benevolencia (TSM VI.conc.5, 263; VI.i.15, 216). Esta distinción entre una prudencia inferior y otra superior revela el reconocimiento por Smith de que la virtud puede adoptar tanto formas nobles como otras menos nobles, y que hasta podría llegar a ser considerada en sí como producto de su aserto de que, efectivamente, "no hay virtud" en el grado común de las cualidades morales o prácticas, dado que la "virtud es excelencia, algo inusualmente grande y hermoso, que se yergue muy por encima de lo que es vulgar y ordinario" (TSM I.i.5.6, 25).

De modo que así como el hombre magnánimo de Aristóteles representa una cumbre de excelencia en las virtudes éticas, así también el hombre de prudencia superior de Smith representa una excelencia política superior a la excelencia individualista, representada por la prudencia inferior. Pero incluso elogiando a este individuo, Smith advierte claramente sus fallas. El amor propio de la prudencia inferior es útil pero de miras cortas; el amor por sí mismo del hombre magnánimo, si bien más elevado que el amor propio de la prudencia inferior, también es potencialmente mucho más destructivo. Con toda la bien intencionada preferencia de los dignos de elogio a ser elogiados, el aspirante a la magnanimidad ocasionalmente tiende a perder de vista al primero por su amor al segundo. Tanto Aristóteles como Smith están profundamente conscientes de los peligros a que puede llevar la excesiva admiración de sí mismo. La imagen del tirano conquistador, cuya avidez de honor lo lleva a la batalla tanto con los hombres como con los dioses, siempre está en las mentes de cualquiera de los dos (TSM VI.iii.28, 250-252). En efecto, esta excesiva admiración de sí mismo, que "encandila a la multitud y despierta su tonta admiración”, sería graciosa de no ser tan peligrosa.

${ }^{31}$ La distinción que hace Smith entre los hombres de prudencia inferior y superior puede compararse con la diferencia entre phronimos y megalopsychos que hace Aristóteles. Hay también otros que han visto la influencia del phronimos aristotélico en la obra de Smith; véase Vivenza (2001: 47-49, 83); Griswold (1999: 204-205); Fleischacker (1999: 120-139). 
Smith nos hará saber que la mejor especie de hombres se basta con "sonreír en secreto" ante tales hombres y sus "extravagantes e infundadas pretensiones” (TSM VI.iii.27, 249-250).

Pero ¿cuáles son los mejores hombres? Habiendo ilustrado los peligros de la magnanimidad, Smith ahora explica cómo comprende él la perfección ética. Su presentación del hombre sabio y virtuoso es, en cierto sentido, análoga a la presentación que hace Aristóteles de la superioridad de la vida contemplativa. Ambos conceptos de autoperfección son efectivamente presentados por sus autores como intentos de trascender los problemas que surgen de la irrestricta competencia por alcanzar nobleza entre los hombres de virtud ética (EN 1169a6-15). Smith insiste particularmente en que los hombres sabios y virtuosos no se contentan con otra cosa que no sea la incesante persecución del honor o de la nobleza. La gloria popular es algo que jamás cortejan, pues "para el hombre realmente sabio la juiciosa y bien ponderada aprobación de un solo hombre de sabiduría entrega una satisfacción más sentida que todos los ruidosos aplausos de diez mil ignorantes aunque entusiastas admiradores” (TSM VI.iii.31. 253). Esta distinción entre los meritorios elogios de jueces informados y las "tontas" alabanzas de la "gente común" o "de la turba de entre los hombres", de hecho es casi una constante a lo largo de la obra de Smith (TSM I.iii.3.8, 64-66; VI.iii.27, 249-250; VI.iii.30, 253). Si bien no siempre tan explícitamente despectivo respecto de la alabanza pública, es evidente que Smith piensa que acariciar esa suerte de elogios se encuentra por debajo de la dignidad del hombre sabio y virtuoso.

Pero al hombre sabio y virtuoso no sólo se le distingue por su disposición respecto al honor. En cierto modo se asemeja al hombre magnánimo. Al igual que éste, el hombre sabio y virtuoso disfruta de esa tan agradable conciencia de haber realizado acciones benéficas. También él actúa a partir de su amor por la nobleza y la reverencia que siente ante la superioridad de su propio carácter. Pero es aquí donde el hombre sabio y virtuoso se aparta del hombre magnánimo. Smith ya había sugerido que la grandeza no consiste simplemente en el amor por la nobleza y aquello más elevado en nosotros, sino que también en la realización que produce: aun el mejor de los hombres no es "sino uno entre la multitud, no mejor que cualquier otro de entre ella" (TSM III.3.4, 137; II.ii.2.1, 82-83; VI.ii.2.2, 227-228). Pero es precisamente esto lo que los hombres magnánimos no pueden aceptar. Incluso si desprecian el honor, su búsqueda de nobleza está no obstante contaminada por su deseo de superioridad, y ese amor por la superioridad les impide la plena aceptación de su "verdadera pequeñez" (TSM III.3.4, 137). Los hombres sabios y virtuosos, sin embargo, siempre llevan consigo el imperativo de precisamen- 
te aquello que Alejandro, César y Sócrates olvidaron. A diferencia de los hombres magnánimos, que constantemente se comparan con los demás, el hombre sabio y virtuoso tiene presente ante sí un estándar más elevado de perfección absoluta. Sin olvidar jamás que existen varas más altas que la de los otros, siempre "se sentirá mucho más humillado por la comparación con ese primer estándar de lo que jamás podrá ser elevado por la vara de los otros”. Recordando con "preocupación y humillación” cuán lejos puede llegar a estar de la imagen de la perfección absoluta que siempre lleva consigo, nunca olvida su verdadera pequeñez. Sin embargo, la comprensión que tiene el hombre sabio y virtuoso de los límites de la perfectibilidad humana no lo conduce simplemente a rechazar el camino de la propia perfección y a abrazar la humildad. En vez de esto, esa comprensión establece los fundamentos de una visión moderna de la propia autoperfección. La resultante combinación de profundo orgullo y profunda humildad determina no sólo el concepto que tiene de sí mismo sino también sus relaciones con los otros:

Nunca estará tan exaltado como para mirar hacia abajo con insolencia, ni siquiera a los que realmente están por debajo de él. Tiene tan cabal percepción de su propia imperfección, conoce tan bien la dificultad con que logró su propia y remota aproximación a la rectitud, que no puede mirar con desdén la imperfección todavía mayor de otras personas. Lejos de insultarlas por su propia inferioridad, las mira con la más indulgente conmiseración, y con su consejo tanto como con su ejemplo, está en todo momento dispuesto a promover su ulterior progreso. (TSM VI.iii.25, 247-248.)

Incluso consciente de su genuina superioridad, no siente interés en ostentar esa superioridad ante sus inferiores. La suya es, por el contrario, una disposición decididamente más humana ${ }^{32}$.

Ahora bien, ¿cómo puede el hombre sabio y virtuoso promover el bienestar de otros a través del consejo y del ejemplo? Smith entrega una pista en otra parte. "Las disquisiciones políticas", explica, "cuando son justas, razonables y practicables, son las más útiles entre todos los trabajos de especulación” (TSM IV.1.11, 187). De ser verdad, los empeños de la especulación política podrían restituir a la teoría la posibilidad de que ella

${ }^{32}$ De modo similar, la autosuficiencia de Aristóteles requiere no de trascendencia, sino de una correcta relación con los amigos, la familia y los conciudadanos; véase EN 1097b6-11. Uno debe permanecer cerca de otros para ser benefactor (EN 1155a511; 1171a21-27), e incluso la contemplación se beneficia con la amistad; cf. Vivenza (2001: 58). 
provea precisamente aquellos beneficios que fueron descuidados por los teóricos que no cumplieron sus deberes activos (TSM VI.ii.3.6, 237). Por supuesto que Aristóteles también concuerda con Smith en que en tanto el fin de la política sea hacer mejores a otros, la indagación en la naturaleza de la política puede ser una clase muy útil de indagación (EN 1099b29-32; 1102a7-13). A la luz de esta similitud es importante notar que tanto la ética de Smith como aquella de Aristóteles concluyen con una nota muy similar que apunta en esta dirección, a saber, la promesa de otro proyecto, explícitamente político, que se levantará sobre el proyecto moral (TSM VII.iv.37, 341-342; cf. EN 1181b12-15). Así, en su capítulo final, Aristóteles nos recuerda que "en las ciencias prácticas el fin no es lograr un conocimiento teórico de las diversas materias, sino más bien ejecutarlas" (EN 1179a351179b2; cf. TSM VII.ii.1.14, 272). Sin embargo, insiste, si uno espera "ayudar a sus propios hijos y amigos a alcanzar la virtud", "primero debe saberse algo de la ciencia de la legislación” (EN 1180a29-34). Más aún, en cuanto la ciencia que apunta a promover la felicidad de los hombres señala lo que es mejor en instancias específicas, podría suceder que no bastara el conocimiento de las reglas generales (EN 1180b7-16; cf. TSM VII.iv.35 sig., 340-342). Por consiguiente, nos corresponde examinar constituciones específicas y sistemas legales positivos para saber más acerca de "cuál es la mejor constitución en términos absolutos, y cuáles son las mejores regulaciones, leyes y costumbres para cualquier forma de constitución dada" (EN 1181b20-22). Éste también parece ser el método de Smith. Él también piensa que otros pensadores sólo han evaluado los regímenes disponibles y han fallado en describirnos el mejor de esos regímenes. Concuerda en que ésta es una información nada de inútil, y es sobre la base de estos estudios que busca seguir adelante y, tal como Aristóteles, indagar en "las reglas naturales de la justicia de modo independiente de toda institución positiva”, para llegar a "una teoría de principios generales que deberían permear y constituirse en el fundamento del derecho de todas las naciones" (TSM VII.iv.37, 341-342). Si La Teoría de los Sentimientos Morales de Smith quiso en un cierto sentido ser la moderna Ética a Nicómaco, la disquisición política a que se encamina el pensador al final de su ética bien podría ser su Política ${ }^{33}$.

Smith, por cierto, nunca completó esta disquisición política, pero al menos fue lo suficientemente lejos como para entregarnos ciertos indicios de hacia dónde se encaminaba. En lo que quedó a nuestra disposición

${ }^{33}$ Tal vez Smith no esté sólo en este sentido; véase el contundente argumento de John Danford en favor de la segunda Enquiry de Hume como una “'Ética Nicomaquea' para la sociedad mercantil liberal, una ética congruente con la situación política del hombre moderno" (Danford, 1990: 161). 
podemos observar al hombre sabio y virtuoso operando. La Riqueza de las Naciones abre con una advertencia a los filósofos. Con todo el solaz que puedan hallar en su superioridad, Smith les recuerda que por naturaleza no son, de hecho, mejor que un porteador ( $R N$ I.ii.4, 28-29). Pero Smith no sólo recuerda al filósofo que el porteador es su igual, sino que también le recordará que tal vez le deba al porteador algo más que sólo un pequeño deber activo. "Los genios más disímiles son de utilidad el uno para el otro" ( $R N$ I.ii.5, 30). Es bastante fácil imaginar cómo los porteadores pueden servir a los filósofos, pero, ¿cómo puede servir el filósofo al porteador?

Las Lectures on Jurisprudence nos hacen una sugerencia. Allí aprendemos que "en cuanto a su utilidad, incluso la sabiduría y la virtud en todas sus facetas derivan su brillo y su belleza meramente de su tendencia a garantizar la seguridad de la especie humana" respecto de sus necesidades y comodidades. De modo que la sabiduría y la virtud no son descubiertas en el honor o en la nobleza, sino que en el cumplimiento de fines que comúnmente han sido considerados como "el objetivo del trabajo de tan sólo los vulgares". Este enfoque parece un reproche para aquellos que consideran semejante banalidad como algo inferior a ellos. Tal vez es a éstos a quienes Smith dirige su observación de que:

En una cierta mirada sobre las cosas, las diversas artes, las ciencias, el derecho y el gobierno, la sabiduría y hasta la virtud misma tienden todas a esta sola cosa: proveer carne, bebida, vestuario y techo para los hombres, labores que comúnmente son tenidas como inferiores y aptas tan sólo para las más bajas y miserables de entre las personas ( $L J$ (A) vi.20-21, 338 $)^{34}$.

Pero éste es, por supuesto, el proyecto de la Riqueza de las Naciones, que apunta a realizar el mejoramiento práctico de la condición de los pobres mediante el logro de "esa opulencia universal que se extenderá hasta las personas de los estratos más bajos” (RN I.i.10, 22). Podría decirse que

${ }^{34}$ Sin embargo, esta formulación lo lleva a uno a preguntarse si acaso la definición de Smith de los conceptos sabiduría y virtud no sucumbe a la crítica aristotélica de las amistades desiguales. La defensa que hace Aristóteles de la contemplación es presentada en parte como un intento por establecer una amistad genuinamente igualitaria en contraste con las amistades desiguales, en que una parte cosecha lo meramente útil y la otra lo noble (EN 1168a9-12). Pero, al mismo tiempo, la definición que da Smith de la sabiduría y de la virtud parece querer remediar una cierta falencia en aquella presentación de Aristóteles que los lectores modernos titubean en aceptar. Aristóteles traza una rígida línea de demarcación entre los gentilhombres y los filósofos, pero el hombre sabio y virtuoso de Smith parece aspirar a una reconciliación entre las virtudes éticas y las intelectuales; cf. Den Uyl y Griswold (1996: 634). 
es a través de la autoría de la Riqueza de las Naciones que Smith ofrece su propia persona como ilustración del carácter de la sabiduría y la virtud. En particular, la autoría de Smith está destinada a mostrar en qué forma las virtudes éticas del hombre sabio y virtuoso pueden ser armonizadas con las virtudes intelectuales del teórico político. Y en cuanto este carácter también representa el intento de recuperar una comprensión de la autoperfección informada profundamente por Aristóteles, podría asimismo apuntar a otro mecanismo para la "preservación de aspectos deseables del pensamiento antiguo" en el seno de la modernidad (Griswold, 1999: 7).

\section{REFERENCIAS BIBLIOGRÁFICAS}

\section{a) Abreviaciones y referencias de las obras citadas de Adam Smith}

$\begin{array}{ll}\text { LJ } & \text { Lectures on Jurisprudence. } \\ \text { LRBL } & \text { Lectures on Rethoric and Belles Lettres. } \\ R N & \text { La Riqueza de las Naciones } \\ & \text { [WN, The Wealth of Nations]. } \\ \text { LSM Teoría de los Sentimientos Morales } & \text { [TMS, The Theory of Moral Sentiments]. }\end{array}$

Las referencias siguen las divisiones, párrafo(s) y finalmente página(s) de las ediciones en inglés de Liberty Fund, que son reproducciones fotográficas de las publicadas por Oxford University Press, basadas a su vez en la edición emprendida por la Universidad de Glasgow:

(LJ) Lectures on Jurisprudence. R. L. Meek, D. D. Raphael y P. G. Stein (eds.). Indianápolis: Liberty Fund, 1982 [Oxford University Press, 1978].

(LRBL) Lectures on Rethoric and Belles Lettres. J. C. Bryce y A. S. Skinner (eds.). Indianápolis: Liberty Fund, 1995 [Oxford University Press, 1983].

(RN) An Inquiry into the Nature and Causes of the Wealth of Nations [WN 1776]. R. H. Campbell y A. S. Skinner (eds.). Indianápolis: Liberty Fund, 1981 [Oxford University Press, 1976, 1979].

(TSM) The Theory of Moral Sentiments [TMS 1759]. D. D. Raphael y A. A. Macfie (eds.). Indianápolis: Liberty Fund, 1984 [Oxford University Press, 1976, 1979].

\section{b) Otros autores citados}

Anscombe, G. E. M.: “Modern Moral Philosophy”. En Philosophy, 33 (1958), p. 119 [Reproducido en G. E. M. Anscombe, Ethics, Religion and Politics Minneapolis, MN: University of Minnesota Press, 1981.]

Aristotle: (EN) Nicomachean Ethic. Traducido al inglés por H. Rackham. Cambridge, MA: Harvard University Press, 1934.

Aristotle: $(R)$ Rhetoric. Traducción al inglés por G. A. Kennedy. Oxford: Oxford University Press, 1991. 
Aristotle: Politics. Traducción al inglés por H. Rackham. Cambridge, MA: Harvard University Press, 1932.

Baier, A.: “Doing Without Moral Theory”. En A. Baier, Postures of the Mind: Essays on Mind and Morals. Minneapolis, MN: University of Minnesota Press, 1985.

Berns, L.: "Aristotle and Adam Smith on Justice: Cooperation between Ancients and Moderns?” En Review of Metaphysics, 48 (1994), pp. 71-90.

Buckle, S.: “Aristotle's Republic: or Why Aristotle’s Ethics Is Not Virtue Ethics”. En Philosophy, 77 (2002), pp. 565-595.

Calkins, M. J. y Werhane, P. H.: “Adam Smith, Aristotle, and the Virtues of Commerce”. En Journal of Value Inquiry, 32 (1998), pp. 43-60.

Carrasco, M. A.: “Adam Smith's Reconstruction of Practical Reason”. En Review of Metaphysics, 58 (2004), pp. 81-116.

Copp, D. y D. Sobel: "Morality and Virtue: An Assessment of Some Recent Work in Virtue Ethics”. En Ethics, 114 (2004), pp. 514-554.

Cropsey, J.: Polity and Economy. South Bend, IN: St. Augustine’s Press, [1957] 2001.

Danford, J.: David Hume and the Problem of Reason. New Haven, CT: Yale University Press, 1990.

Darwall, S.: Virtue Ethics. Oxford: Blackwell, 2003.

Den Uyl, D.: The Virtue of Prudence, Nueva York: Peter Lang, 1991.

"Shaftesbury and the Modern Problem of Virtue". En Social Philosophy and Policy, 15 (1998), pp. 275-316.

Den Uyl, D. y C. Griswold: “Adam Smith on Friendship and Love”. En Review of Metaphysics 49 (1996), pp. 609-637.

Fleischacker, S.: A Third Concept of Liberty: Judgement and Freedom in Kant and Adam Smith. Princeton, NJ: Princeton University Press, 1999.

Frankena, W.: "Beneficence / Benevolence". En Social Philosophy and Policy, 4 (1987), pp. 1-20.

Griswold, C.: Adam Smith and the Virtues of Enlightenment, Cambridge: Cambridge University Press, 1999.

Hanley, R. P.: “Aristotle on the Greatness of Greatness of Soul”. En History of Political Thought, 23 (2002), pp. 1-20.

Hollander, S.: “Adam Smith and the Self Interest Axiom”. En Journal of Law and Economics 20 (1977), pp. 133-152.

Homiak, M.: “Hume’s Ethics: Ancient or Modern?” En Pacific Philosophical Quarterly, 81 (2000a), pp. 215-236.

"Does Hume Have an Ethics of Virtue? Some Observations on Character and Reasoning in Hume and Aristotle”. En M. Gedney (ed.), The Proceedings of the Twentieth World Congress of Philosophy, VII. Bowling Green, OH: Bowlig Green State University Press, 2000b.

Hursthouse, R.: "Virtue Ethics and Human Nature”. En Hume Studies, 25 (1999a), pp. 67-82.

On Virtue Ethics. Oxford: Oxford University Press, 1999b.

Jaffa, H. V.: Thomism and Aristotelianism. Chicago: University of Chicago Press, 1952.

Kraut, R.: Aristotle on the Human Good. Princeton, NJ: Princeton University Press, 1989. 
Lear, G. R.: Happy Lives and the Highest Good. Princeton, NJ: Princeton University Press, 2004.

Lerner, R.: "Love of Fame and the Constitution of Liberty". En T. Angerer (ed.), Geschichte und Recht. Viena: Böhlau Verlag, 1999.

Livnat, Y.: “On the Nature of Benevolence”. En Journal of Social Philosophy, 35 (2004), pp. 304-317.

Macfie, A. L.: The Individual in Society. Londres: Methuen, 1967.

MacIntyre, A.: After Virtue. South Bend, IN: Notre Dame University Press, 1984.

"Virtue Ethics". En L. C. Becker y C. B. Becker (eds.), Encyclopedia of Ethics. Londres: Routledge, 2001.

Montes, L.: Adam Smith in Context: A Critical Reassessment of Some Central Components of his Thought. Londres: Palgrave Macmillan, 2004.

Nussbaum, M.: “Virtue Ethics: A Misleading Category?” En Journal of Ethics, 3 (1999), pp. 163-201.

Sherman, N.: The Fabric of Character: Aristotle's Theory of Virtue. Oxford: Oxford University Press, 1989.

Simpson, P.: "Contemporary Virtue Ethics and Aristotle”. En Review of Metaphysics, 45 (1992), pp. 503-504.

Singleton, J.: "Virtue Ethics, Kantian Ethics, and Consequentialism". En Journal of Philosophycal Research, 27 (2002), pp. 531-551.

Skinner, A. S.: A System of Social Science: Papers Relating to Adam Smith. Oxford: Oxford University Press, 1979.

Slote, M.: "Virtue Ethics". En H. LaFollete (ed.), The Blackwell Guide to Ethical Theory. Oxford: Blackwell, 2000.

Stohr, K. y C. Wellman: “Recent Work on Virtue Ethics”. En American Philosophycal Quarterly, 39 (2002), pp. 49-72.

Tessitore, A.: Reading Aristotle's 'Ethics': Virtue, Rhetoric, Political Philosophy. Albany, NY: State University of New York Press, 1998.

Trianosky, G.: "What is Virtue Ethics All About? Recent Work on the Virtues". En American Philosophical Quarterly, 27 (1990), pp. 335-344.

Vivenza, G.: Adam Smith and the Classics: The Classical Heritage in Adam Smith's Thought. Oxford: Oxford University Press, 2001.

- "Reading Adam Smith in Light of the Classics". En Adam Smith Review, 1 (2004), pp. 107-124.

Waszek, N.: “Two Concepts of Morality: A Distinction of Adam Smith's Ethics and its Stoic Origins”. En Journal of the History of Ideas, 45 (1984), pp. 591-606.

Werhane, P.: Adam Smith and his Legacy for Modern Capitalism. Oxford: Oxford University Press, 1991. 